\title{
Why Do Modified Numerals Resist a Referential Interpretation?
}

\author{
Carla Umbach \\ University of Osnabrück
}

\section{Introduction}

It is well known that bare numerals license a specific, or referential reading, whereas modified numerals do not. For example, three boys in (1a) can take wide scope over the subject NP resulting in a reading where three particular boys were visited by every girl, whereas at least three boys in (1b) cannot take wide scope.

a. Every girl visited three boys.

b. Every girl visited at least three boys.

The difference between (la) and (lb) is commonly explained by the fact that scope inversion is possible if the NP has a referential reading. In general, the fact that a wide scope reading is available for bare numerals, but not for modified numerals, is taken to show that modified numerals, in contrast to bare numerals, cannot have a referential reading. In this paper a semantic explanation of the difference in referential behavior of bare and modified numerals will be given.

Bare numerals consist of a number determiner and a (possibly complex) noun, e.g., three nice boys from Berlin. Modified numerals in addition include a preceding particle like at least, at most, more than, less than. In order to compare bare and modified numerals there are basically two options: Either the combination of particle and number word is regarded as a distinct determiner different from the number word determiner, cf. (2a). Then the difference in referential behavior has to be traced back to a difference in the semantics of theses determiners. Or the modified numeral is regarded as being composed of a bare numeral and a modifying particle, cf. (2b). In this case we have to answer the question of why the referential reading of the bare numeral is blocked by the modifier.
a. (DET at least three) (boys)
b. (at least (NP three boys))

In this paper we will consider three accounts relating to the contrast between bare and modified numerals: Szabolci (1997), de Swart (1999), and Krifka (1999). Szabolcsi and de Swart regard bare numerals and modified numerals as comprising distinct determiners but provide different explanations for their semantic differences. Krifka adopts the second perspective. He suggests interpreting expressions like at least and at most as focus-sensitive adverbs, 
which apply, amongst others, to bare numeral NPs. It will be shown that this interpretation, although intended to solve a problem not related to the referential behavior of bare and modified numerals, provides a natural explanation for the fact that in the case of the modified numeral the referential reading is blocked.

The paper is organized as follows: In section 2 Szabolcsi's distinction between quantifier readings and referential readings is explained, and additional data from German are provided supporting her claim. Section 3 and 4 briefly look at the DRT representation of bare vs. modified numerals (cf. Kamp and Reyle 1993), and at the meaning of others and the other, which plays a prominent role in distinguishing quantificational and referential readings. In section 5, de Swart's identity criterion for referential (type e) interpretations is discussed. In section 6 and 7, Krifka's interpretation of at least and the explanation for the behavior of modified numerals resulting from his account are presented. Finally, unresolved problems and questions for future analyses are identified.

\section{Quantificational vs. Referential Readings}

\subsection{Support of Non-Maximal Reference Anaphors}

Szabolcsi (1997) argues against a uniform treatment of noun phrases employing a single "semantically blind" rule of scope assignment. She is mainly concerned with Hungarian data but her claims also pertain to English. Based on Beghelli's and Stowell's (1997) proposal for LF positions in English, Szabolcsi shows that the interpretation of an NP may vary according to its position in LF, where some NPs may occur in more than one position while others are restricted to a single position. We will focus on the semantic aspects of this account: Szabolcsi assumes that there are basically two options for the interpretation of a noun phrase: Either it contributes an entity to the interpretation of the sentence which serves as a (logical) subject of predication, or it performs a counting operation on the property denoted by the rest of the sentence. In the former case the NP denotes an (atomic or plural) individual corresponding to a minimal witness set of the NP, in the latter case it denotes a generalized quantifier. We will call the first reading referential and the second one quantificational.

The question of whether a noun phrase must be interpreted quantificationally or may also allow a referential interpretation, first of all depends on monotonicity properties. Noun phrases corresponding to monotone decreasing or non-monotone quantifiers can only achieve a quantificational interpretation. Noun phrases corresponding to monotone increasing quantifiers may achieve a referential interpretation (depending on their LF position). This is explained by the fact that upward monotonicity guarantees that using a minimal witness set preserves truth conditions. However, modified numerals like at least / more than three boys, although monotone increasing, do not license a referential 
interpretation. Thus Szabolcsi requires an additional characteristic for NPs to achieve a referential interpretation, which is support of non-maximal reference anaphors. It is demonstrated in (3).

(3) a. Two boys were selling coke. They were wearing black jackets. Perhaps there were others (... but I didn't notice).

b. At least two boys were selling coke. They were wearing black jackets. \# Perhaps there were others (... but I didn't notice).

In (3a) the pronoun they may refer to a subset of the boys selling coke. There may have been more than two boys selling coke, but the pronoun need not refer to all of them, which is indicated by the continuing sentence "Perhaps there were others ..." (that is, other boys selling coke, cf. section 4). Thus the bare numeral in (3a) supports non-maximal reference anaphors. In (3b) the pronoun they must refer to the entire set of boys selling coke. For this reason the continuation "Perhaps there were others..." is infelicitous. Obviously, the modified numeral in (3b) supports only maximal reference anaphors.

To provide a semantic representation, Szabolcsi employs (a modified version of $\mathrm{DRT}^{2}$ The distinction between a referential and a quantificational reading is reflected by the DRT distinction between the direct introduction of a discourse referent and the introduction of a duplex condition plus subsequent abstraction operation (cf. section 3). Support of non-maximal reference anaphors indicates that the NP directly introduces a discourse referent, without making use of the properties given in the rest of the sentence. This is why support of nonmaximal reference anaphors indicates that the NP has a referential reading.

In other words, there are two requirements for a numeral to get a referential interpretation, upward monotonicity and support of non-maximal reference anaphors. Support of non-maximal reference anaphors provides an adequate descriptive criterion to distinguish between bare numerals and (increasing) modified numerals, filtering out, e.g., at least / more than three boys. Still, it does not offer a semantic explanation of why modified numerals cannot have a referential interpretation. ${ }^{3}$

\subsection{German Numerals in Topic Position}

In Umbach (2004a) it is shown that German bare numerals in topic position, with a focus on the determiner, facilitate two readings, a quantificational one and a specific, or referential one. These readings differ with respect to the alternatives evoked by the focus, which are indicated in the respective continuations. Consider (4a) and (b). Mr. Paul and Mr. Grün are supposed to be local business men in some small town, who have been asked to provide internships for a group of local 
students. (Accents on the relevant determiners are capitalized, other accents are omitted.)

a. Mr. Paul:

ZWEI Schüler würde ich nehmen. Aber fünf [Schüler] sind mir zuviel.

'I would take two students but five are too many for me.'

b. Mr. Grün:

ZWEI Schüler würde ich nehmen. Die anderen [Schüler] lieber nicht.

'I would take two of the students. The others I'd rather not take.'

In Mr. Paul's answer in (4a) the bare numeral NP ZWEI Schüler 'two students' is in contrast with fünf [Schüler] 'five students'. Thus the alternative set triggered by the NP consists of student-quantifiers of different cardinality: \{one student, two students, three students ...\}, indicating that the NP is interpreted quantificationally. In Mr. Grün's answer in (4b) the NP ZWEI Schüler is in contrast with die anderen [Schüler] 'the other students'. ZWEI Schüler refers to a particular subgroup of a previously mentioned student group, and die anderen [Schüler] in the second sentence refers to the complement (cf. section 4). In this case the alternative set triggered by ZWEI Schüler comprises two elements, which are both (plural-)individuals: \{two of the students, the other students\}, indicating that the NP has a referential reading.

Taking the two readings of the bare numeral into account it is predicted that modified numerals will be appropriate in contexts like (4a), when contrasted with another quantifier, but that they are infelicitous in (4b). This is confirmed by the data. In (5) Mindestens / mehr als ZWEI Schüler 'at least/more than two students' is contrasted with höchstens fünf [Schüler] 'at most five students', which is acceptable. (Note, however, that the second quantifier has to be a modified numeral instead of a bare numeral.) In (6) Mindestens / mehr als ZWEI Schüler is contrasted with die anderen [Schüler], which is not acceptable.

(5) Mr. Paul:

Mindestens / mehr als ZWEI Schüler würde ich nehmen. Aber höchstens fünf.

'I would take at least /more than two students but at most five.'

Mr. Grün:

\# Mindestens / mehr als ZWEI Schüler würde ich nehmen. Die anderen lieber nicht.

'I would take at least / more than two students. The others I'd rather not take.'

These examples support Szabolsci's claim that bare numerals may have a quantificational and a referential reading and present further evidence for the fact that modified numerals license only quantificational interpretations. They provide 
another test for the support of non-maximal reference anaphors slightly differing from Szabolcsi's in that they function without an additional pronoun and make use of the definite complement anaphor die anderen 'the others'.

\section{Introduction of Discourse Referents vs. Introduction of Duplex Conditions}

Concerning numerals, standard DRT doesn't allow two different interpretations of bare numerals - three boys are uniformly interpreted by introducing a plural discourse referent. But modified numerals are interpreted in a different way. Instead of introducing a discourse referent they introduce a duplex condition. This accounts for the fact that modified numerals support only maximal reference anaphors. Compare (7) and (8):

(7) a. Two boys were selling coke. They were wearing black jackets.

b.

\begin{tabular}{|l|}
\multicolumn{1}{|c|}{$\mathrm{X} \mathrm{Y}$} \\
boy $(\mathrm{X})$ \\
sell-coke $(\mathrm{X})$ \\
$|\mathrm{X}|=2$ \\
$\mathrm{Y}=\mathrm{X}$ \\
wear-black-jackets $(\mathrm{Y})$ \\
\hline
\end{tabular}

(8) a. At least two boys were selling coke. They were wearing black jackets.

b.

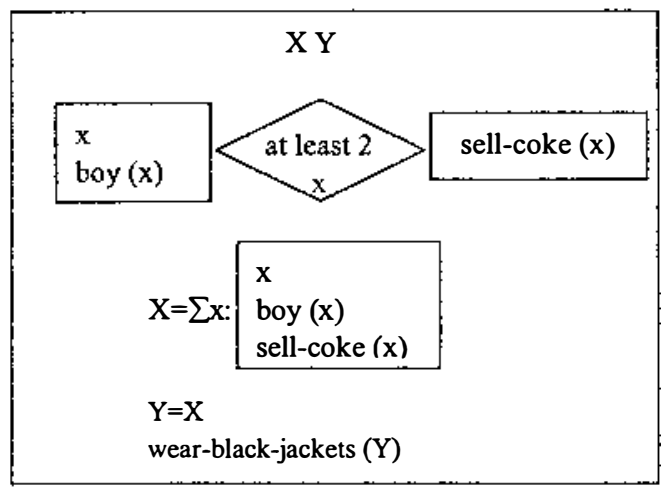

The bare numeral in (7) introduces a plural discourse referent $\mathrm{X}$ which is the antecedent for the pronoun in the second sentence. This referent is subject to the 
conditions given by the NP, that is, it has to be a group of two boys. The modified numeral in (8) introduces a duplex condition. To interpret the pronoun an antecedent is belatedly formed by abstraction. Note that the discourse referent formed by abstraction makes use of the restrictor and the nuclear scope of the duplex condition. It includes all boys who were selling coke. This is why the pronoun in (8) must be a maximal reference anaphor, whereas the one in (7) may be non-maximal referring to any subset of coke-selling boys with two elements. Thus, the DRT distinction between, on the one hand, directly introducing a discourse referent, and on the other hand, introducing a duplex condition perfectly captures Szabolcsi's claim that a noun phrase either contributes an entity which is subject to a predication, or it performs a counting operation on the property given in the reminder of the sentence. ${ }^{4}$ Still, this doesn't explain why bare and modified numerals differ the way they do.

\section{4. (The) Others}

Since in the example in (3), which demonstrates support of (non-)maximal reference anaphors, the NPs others / the others play an important role, we will take a brief look at their interpretation. Following Kamp (2001) other is an adjective denoting the property of being distinct from another individual. Being distinct is represented by a two-place predicate, \#, where " $\alpha \# \beta$ " is false if $\alpha$ and $\beta$ are identical, or one of them is included in the other one (where $\alpha$ and $\beta$ represent atomic or plural individuals). Since being different presupposes some kind of similarity, $\alpha$ and $\beta$ must share a common property $C$ (which has to be backgrounded). 5

Without going into details, let us assume that others is an indefinite NP including an implicit head noun (other $N s$ ). It introduces a (plural) discourse referent $\mathrm{X}$ which has to be distinct from a presupposed co-referent $\beta$ such that they share a common property (corresponding to the implicit head noun): $X \# \beta$, $C(X), C(\beta)$.

In the example in (3a), repeated in (9a), the co-referent is clearly the referent of the pronoun they, that is, the discourse referent denoted by three boys. Thus the property to be shared is the property of being a boy. Accordingly, the $\mathrm{NP}$ others introduces a group of boys distinct from the three boys introduced in the first sentence. Similarly, in $(9 b)(=3 b)$ the preferred co-referent is the referent of the pronoun they. In this case it refers to a discourse referent established by abstraction, including all boys selling coke. Thus the property to be shared should be the property of being a boy selling coke. But then a conflict arises because others introduces a discourse referent which shares the property of being a boy selling coke and at the same time is required to be distinct from all boys selling coke. This is why the continuation in (9b) is not acceptable. 
There is, however, a caveat concerning the use of others in (9b): It might also be interpreted with respect to a different common property, as for example other persons selling coke, cf. (9c). In this case the referent established by abstraction is a perfect co-referent, and hence the third sentence is an acceptable continuation. (Note that this interpretation is facilitated by an accent on boys.)
a. Two boys were selling coke. They were wearing black jackets. Perhaps there were others (... but I didn't notice).
b. At least two boys were selling coke. They were wearing black jackets. \# Perhaps there were others (... but I didn't notice).
c. At least two boys were selling coke. They were wearing black jackets. Perhaps there were other persons also selling coke, but I didn't notice.

A similar caveat applies to the examples in (4b) and (6), repeated in $(10 a, b)$. Here we find a definite NP (die anderen, 'the others'), thus requiring maximality with respect to the common property $\mathrm{C}$ minus the co-referent. Similar to (9b), the coreferent is established by abstraction comprising all students of the aforementioned student group accepted by Mr. Grün, which does not allow for a complement denoted by die anderen. As before, this conflict is the reason why the continuation in (10b) is not acceptable. In (10c), however, an apposition is inserted naming the students Mr. Grün has in mind. Due to the insertion the continuation is considerably improved. Now die anderen 'the others' can be interpreted as the students different from the grandsons of Grün's neighbour.

(10) Mr. Grün:

a. ZWEI Schüler würde ich nehmen. Die anderen lieber nicht. 'I would take two of the students. The others I'd rather not take.'

b. \# Mindestens ZWEI Schüler würde ich nehmen. Die anderen lieber nicht.

'I would take at least two of the students. The others I'd rather not take.'

c. Mindestens ZWEI Schüler würde ich nehmen, nämlich die Enkel meines Nachbarn. Die anderen lieber nicht. 'I would take at least two of the students, namely the grandsons of my neighbour. The others I'd rather not take.'

It is important to note that, contrary to what is often said in the literature, the namely-insertion does not indicate a specific, or referential reading in (10c). Instead it indicates a general problem with namely-insertions: They can be used even if the NP is clearly quantificational, cf. (11). Most and few are above suspicion concerning referential readings because they denote a strong and a downward monotone determiner, respectively. The namely-insertion introduces a discourse referent which is identified with a referent established by abstraction. 
This is why in (11) the participants in the final meeting are identical to the speaker's students who passed the exam.

(11) Most/few students of mine passed the exam, namely those who participated in the final meeting. The others failed.

\section{The Identity Criterion}

In de Swart (1999) a classification of indefinite NPs is proposed which is based on semantic properties of the NP denotations. Adopting a type shifting perspective where NPs may have a family of interpretations of type e, type $<e, t>$, and type $<<e, t>, t>$ (cf. Partee 1987), three classes of indefinites are distinguished: Class I indefinites are weak, that is, felicitous in existential contexts. They are interpreted as generalized quantifiers (type $<<e, t>, t>$ ) and they must have a denotation which, after application of Partee's type shifting operator BE, is neither empty nor a singleton. This characterization filters out strong quantifiers and also definite NPs. Class II indefinites constitute a subclass of class I. They are referential in the sense that they pick out a (possibly plural) individual thereby establishing a discourse referent. Thus their denotation is of type e. Class III indefinites, which are also a subclass of weak indefinites, may appear in a predicative position and are interpreted as properties (type $<e, t>$ ).

We will focus on class II indefinites. Being monotone increasing is a necessary but not sufficient criterion, since modified numerals have to be excluded. In connection with this problem, de Swart poses the question of why bare numerals have a type e denotation but modified numerals have not, which is the central question in this paper. Adopting Link's (1983) ontology where (plural) individuals constitute a join-semilattice, de Swart assumes a partitioning of the domain according to the size of the individuals, i.e. the number of atoms constituting the individuals. Thus the cells include all and only individuals of the same size.

Bare and modified numerals are then distinguished by their ability to identify a particular cell. Whereas three boys identifies the particular cell containing individuals of size three, at least three boys cannot identify a particular cell, since its denotation includes sets of various sizes. In general, indefinites which identify a particular cell may have a type e denotation and thus qualify as referential (class II) indefinites. This is called the identity criterion, and is in a sense the counterpart to Szabolcsi's support of non-maximal reference criterion.

There are two objections: First, some boys clearly licenses a referential interpretation but fails to identify a particular cell in the same-size partitioning. De Swart actually concedes that in order to extend her idea to some $N$ and many $N$ some room for vagueness has to be allowed in the way the partitioning is built up. However, if the partitioning is weakened to allow for some $N$ to identify a 
particular cell, then there is no reason why at least three $N$ should not do so. To put it another way, the fact that some $N$ is not able to identify a cell is evidence that licensing a type e denotation does not require a natural number size.

Secondly, de Swart further weakens her account by allowing the partitioning of the domain to depend on the context. Although the same-size partitioning is clearly the most natural one, particular contexts may then impose a 'degenerate' partitioning involving only two cells, e.g., individuals with $n$ or more atoms and individuals with less than $n$ atoms. The reason for this are examples which seem to indicate that, in certain contexts, modified numerals (even if nonmonotone or monotone decreasing) may license referential readings. A discussion of these, however, lies beyond the scope of this paper. ${ }^{6}$ In any case, attributing the lack of a referential interpretation to the failure to identify a particular cell seems to shift the burden to the partitioning of the domain without providing an explanation.

\section{At least as a Focus-Sensitive Operator}

The accounts in Szabolsci (1997) and de Swart (1999) both viewed three and at least three as different determiners with a possibly different semantics. Krifka (1999) adopts a compositional perspective interpreting at least as an operator which can be applied to, amongst others, bare numeral phrases. Krifka's paper focuses on the problem that, in spite of the fact that their meaning seems to be the same, bare numerals and modified numerals trigger different scalar implicatures. According to Generalized Quantifier Theory (Barwise and Cooper 1981), both three boys and at least three boys denote quantifiers which allow for more than three elements in the intersection of the restrictor and the nuclear scope. Nevertheless, (12a), but not (12b), triggers the implicature that no more than three boys are selling coke.

(12) a. Three boys are selling coke.

b. At least three boys are selling coke.

Krifka assumes that scalar implicatures are induced by alternatives. Asserting a sentence with a meaning $M$, the speaker conveys the information that she is not willing to assert any of the proper alternatives triggered by $M$ (that is, any alternative $M^{\prime} \neq M$ ), either because the alternative statement is more informative than $M$ violating the Maxim of Quality, or because it is less informative violating the Maxim of Quantity. (12a), for example, given a focus on the number word, triggers alternatives of the form "n boys are selling coke", for $n \in N$. By asserting (12a) the speaker simultaneously conveys the information that she lacks evidence, or has counterevidence, for any number $n>3$, and that she has evidence that $\mathrm{n}>2$. 
Concerning at least, Krifka's analysis starts from two observations. First, the meaning of at least is sensitive to accent. This is demonstrated in (13) (Krifka's example 14). (13a) means that the number of boys that left is at least three, while (13b), assuming that the focus includes three boys, means that the persons that left include three boys.
a. At least THREE boys left.
b. At least [three BOYS $]_{F}$ left.

Secondly, unlike genuine determiners like every, some and most, expressions like at least, at most, less than, more than, exactly combine, e.g., with NPs, adjectives, and VPs, cf. (14a-f) (Krifka's example 16-18). ${ }^{7}$

(14) a. John saw at least Mary.

b. The aggressors wanted more than the southern province.

c. Mary was at least satisfied.

d. We are more than happy to serve you.

e. The guest at least left early.

f. He at most spanked the child.

These data suggest that there is a general meaning of at least which operates on a focus, similar to the focus-sensitive adverb only, such that the meaning of at least three boys is composed of the general meaning of at least and the meaning of three boys.

Krifka adopts the two dimensional-interpretation of focus suggested by Rooth (1992) where any expression $\alpha$ has an alternative meaning $[[\alpha]]^{\mathrm{A}}$ in addition to its ordinary meaning $[[\alpha]]^{0}$. The alternative meaning of a focused expression consists in the set of alternatives triggered by the ordinary meaning, and is projected to the alternative meaning of composed expressions. Different from Rooth, Krifka assumes alternative sets to be partially ordered by, e.g., the order on natural numbers or the part-of relation on plural individuals or a concept taxonomy, depending on the context. The ordering is preserved in the composition of complex alternative meanings.

For number determiners the ordering is naturally given by natural numbers. Hence the alternative meaning of three boys consists of pairs (representing the ordering relation) of $m$ boys and $n$ boys for all $\mathrm{m}, \mathrm{n}$ in N. (15) demonstrates the ordinary meaning and the alternative meaning of three boys. ${ }^{8}$

$$
\begin{aligned}
\text { a. }\left[\left[\text { THREE }_{\mathrm{F}} \text { boys }\right]\right]^{0}=\lambda Q \exists X .|X| \geq 3 \wedge \operatorname{boy}(X) \wedge \mathrm{Q}(\mathrm{X}) \\
\text { b. }\left[\left[\mathrm{THREE}_{\mathrm{F}} \text { boys }\right]\right]^{\mathrm{A}}=\{<\lambda \mathrm{Q} \exists \mathrm{X} .|\mathrm{X}| \geq \mathrm{n} \wedge \operatorname{boy}(\mathrm{X}) \wedge \mathrm{Q}(\mathrm{X}), \\
\left.\qquad \lambda \mathrm{Q} \exists \mathrm{X} .|\mathrm{X}| \geq \mathrm{m} \wedge \operatorname{boy}(\mathrm{X}) \wedge \mathrm{Q}(\mathrm{X})>\mid \mathrm{n} \leq_{\mathrm{N}} \mathrm{m}\right\}
\end{aligned}
$$


The general meaning of at least aimed at in Krifka's paper has to fulfill two requirements: It has to apply to the denotations of NPs, adjectives, VPs etc. in order to cover the examples in (14), and it must use up the alternatives given by the alternative meaning of the argument in order to prevent unwanted implicatures. The basic idea is that general meaning of at least consists in the union of the argument's alternatives which are greater than the argument's ordinary meaning. This is the reason why alternative sets come with an ordering relation. To fulfill the second requirement the alternative meaning of at least is defined in such a way that no proper alternatives, different from the ordinary meaning, survive. The definition of general meaning of at least is given in (16).

$$
\begin{aligned}
& \text { a. }[[\text { at least } \alpha]]^{0}=\cup\left\{P \mid\left\langle[[\alpha]]^{0}, P>\in[[\alpha]]^{A}\right\}\right. \\
& \text { b. }[[\text { at least } \alpha]]^{A}=\{\alpha,\langle\alpha, \alpha>\}
\end{aligned}
$$

The union operation in (16a) is the general join, cf. Keenan and Faltz (1985). We will come back to this in the next section. The alternative meaning in (16b) is called the "standard alternatives". It is defined this way for purely technical reasons and does not include any proper alternatives. (17) shows the result of applying at least to three boys. Note that concerning the ordinary meaning, the result does not differ from the standard interpretation of at least three boys.

$$
\text { a. } \begin{aligned}
& {\left[\left[\text { at least }\left[\text { THREE }_{\mathrm{F}} \text { boys] }\right]\right]^{0}\right.} \\
& =\cup\left\{\mathrm{P} \mid<\left[\left[\mathrm{THREE}_{\mathrm{F}}\right.\right. \text { boys]] }\right. \\
& =\cup\{\lambda \mathrm{Q} \exists \mathrm{X} .|\mathrm{X}| \geq \mathrm{n} \wedge \text { boy }(\mathrm{X}) \wedge \mathrm{Q}(\mathrm{X}) \mid \mathrm{n} \geq 3\} \\
& =\lambda \mathrm{Q} \exists \mathrm{X} .|\mathrm{X}| \geq 3 \wedge \operatorname{boy}(\mathrm{X}) \wedge \mathrm{Q}(\mathrm{X})
\end{aligned}
$$

b. [[at least [THREE $\mathrm{F}$ boys] $]]^{\mathrm{A}}=$ the standard alternatives

\section{The Problem of the Blocked Referential Interpretation}

The meaning of at least given in (16) neatly solves Krifka's problem of the missing scalar implicature. While the sentence Three boys are selling coke. generates a set of proper alternatives ( $n$ boys are selling coke, $n \in N, n \neq 3$ ) leading to the implicature that they are deliberately not claimed by the speaker, the sentence At least three boys are selling coke. doesn't generate any proper alternatives and hence there is no scalar implicature.

At the same time, the meaning of at least given in (16) provides a natural solution for the problem addressed in this paper, that is, the problem of why modified numerals resist a referential interpretation. Recall the definition of the general join operation by Keenan and Faltz (1985), given in (18): 
(18) i. If $\Phi, \Psi$ are sentences (type t), then $[[\Phi]] \cup[[\Psi]]=[[\Phi \vee \Psi]]$;

ii. if $\alpha, \beta$ are expressions of type $\langle\sigma, \tau\rangle$, then $[[\alpha]] \cup[[\beta]]=\lambda X .[[\alpha]](X) \cup[[\beta]](X) ;$

iii. If $S$ is a set of meanings of a type that can be conjoined by $\cup$, $\cup S$ is the result of conjoining all elements of $S$ by $\cup$.

The general join operation is a kind of polymorphic disjunction. Making it the basis of the meaning of at least amounts to interpreting at least as a disjunction of the argument's alternatives (greater or equal to the ordinary meaning of the argument). According to this interpretation At least three boys are selling coke. can be paraphrased as (19a) or (19b). Hence we will call it the disjunctive interpretation of at least.

(19) a. Three boys are selling coke, or four boys are selling coke, or...

b. Three boys or four boys or ... are selling coke.

Being defined by disjunction the general join operation is restricted to conjoinable types (roughly speaking, types which end in type t, cf. Partee and Rooth 1983). It can be applied to type $<$ e,t $>$ denotations, i.e. properties, and also to type $<<e, t>$, $t>$ denotations, i.e. quantifiers. But it cannot be applied to type e denotations, i.e. individuals. Let us follow Partee (1987) in assuming that an NP like three boys comes with a family of interpretations of type e, $<e, \downarrow$, and $<<e, \downarrow>, \downarrow$. If [[three boys]] is of type $\langle e, t>$, then [[at least three boys]] is of type $\langle e, t\rangle$. If [[three boys]] is of type $<<e, \downarrow, t>$ then [[at least three boys]] is of type $<<e, t>, t>$. But if [[three boys]] is of type e, the general join operation is undefined. Assuming the disjunctive interpretation, at least can never be applied to an individual, and at least three boys can never denote an individual.

The fact that the disjunctive interpretation of at least excludes individuals both as an argument and as a result is, in the first place, a side effect of the general join operation and its type restrictions. So one might wonder whether it is just a question of playing around with type assignments. Note, however, that the core of the meaning of at least is a disjunction. No matter whether you work in a typed system or an untyped one, if an operation combines denotations by disjunction, individuals will always be excluded, because there is no way to combine individuals by disjunction. ${ }^{9}$

This of course raises the question of how to interpret NPs like at least John, as in (20a). In order to apply at least to proper name NPs let us assume that the ordering of alternatives is given by the part-of relation $s_{i}$ on plural individuals (cf. Link 1983, ' $\mathrm{j} \oplus \mathrm{k}$ ' denotes the sum of the individuals $\mathrm{j}$ and $\mathrm{k}$ ). According to this ordering john $\leq_{i}$ john $\oplus$ bill $\leq_{i}$ john $\oplus$ bill $\oplus$ fred etc. Thus the alternative meaning of John in (20a) consists of the part-of relation on individuals, cf. (20b). Since at least cannot be applied to individuals, the ordinary meaning as well as the elements of the alternative meaning of John have to be type lifted to quantifier 
denotations, cf. (20c). The composition of at least and John is then straightforward yielding a quantifier as a result, cf. (20d).

(20) a. At least John is selling coke (... maybe also Bill).

b. $[[\mathrm{JOHN}]]^{0}=$ john

$\left.[[\mathrm{JOHN}]]^{\mathrm{A}}=\{<\mathrm{x}, \mathrm{y}\rangle \mid \mathrm{x} \leq_{\mathrm{i}} \mathrm{y}\right\}$

c. $[[\mathrm{JOHN}]]^{0}=\lambda \mathrm{P} . \mathrm{P}(\mathrm{john})$

$[[J O H N]]^{A}=\left\{<\lambda P . P(x), \lambda P . P(y)>\mid x \leq_{i} y\right\}$

d. [[at least JOHN $]]^{0}$

$$
\begin{aligned}
& =\cup\left\{\mathrm{P} \mid<[[\mathrm{JOHN}]]^{0}, \mathrm{P}>\in[[\mathrm{JOHN}]]^{\mathrm{A}}\right\} \\
& =\cup\left\{\lambda \mathrm{P} . \mathrm{P}(\mathrm{x}) \mid \text { john } \leq_{\mathrm{i}} \mathrm{x}\right\} \\
& =\lambda \mathrm{P} .(\mathrm{P}(\text { john }) \vee \mathrm{P}(\text { john } \oplus \text { bill }) \vee \mathrm{P}(\text { john } \oplus \text { bill } \oplus \text { fred } \vee \ldots) \\
& =\lambda \mathrm{P} .\left(\exists \mathrm{x} . \text { john } \leq_{\mathrm{i}} \mathrm{x} \wedge \mathrm{P}(\mathrm{x})\right)
\end{aligned}
$$

It is important to recognize that type lifting is not a repair strategy. Instead, it reflects the fact that the meaning of at least is based on disjunction. This is the primary reason why the proper name in (20a) must be interpreted as a quantifier. In general, it's the primary reason why NPs modified by at least, in particular modified numerals, must be interpreted as quantifiers. Consider DRT. In DRT modified numerals are interpreted as quantifiers, which is a posteriori justified because it yields the correct results concerning anaphoric accessibility: Modified numerals support only maximal reference anaphors (cf. section 3). Accepting the disjunctive interpretation of at least, we can argue for a quantifier interpretation from the beginning, and the accessibility facts turn out to be a consequence of this interpretation.

\section{Explicit Disjunction}

Tracing back the problem of the blocked referential interpretation of modified numerals to the disjunctive interpretation raises the question of explicit dis junction. Similar to noun phrases modified by at least, noun phrases combined by disjunction should not license a wide scope reading and should not support non-maximal reference anaphors. Regarding scope this prediction is easily confirmed: (21) does not allow for a wide scope interpretation.

(21) Every girl kissed three boys or four boys. 
Regarding support of non-maximal reference anaphors, the data are more complex. Let us first consider proper names. The example in (22) is felicitously continued by "Perhaps there are others ...", indicating that the NP John or Bill does support non-maximal reference anaphors. But the pronoun they clearly refers to the sum of John and Bill, and the co-referent of others is john $\oplus$ bill, that is, others refers to persons distinct from John and from Bill. So the others-test fails with this type of example. Still, the fact that the pronoun inevitably refers to the sum of John and Bill is good reason to argue that John or Bill cannot have a referential reading.

(22) John or Bill are selling coke. They are wearing black jackets.

Perhaps there are others also selling coke (... but I didn't notice).

The problematic case is the one in (23) where numbers are combined by disjunction. The continuation with "Perhaps there are others ..." is acceptable, and the others are clearly boys distinct from the three or four boys mentioned in the first sentence. Thus the NP does license a referential interpretation. Is (23) a counterexample to our claim that individuals cannot be combined by disjunction?

(23) Three or four boys are selling coke. They are wearing black jackets.

Perhaps there are others also selling coke (... but I didn't notice).

Intuitively, three or four boys in (23) is very much like some boys, which also has a referential reading. From this point of view, three or four boys does not denote the coordination of two specific groups of boys, i.e. three particular boys or four particular boys. Instead, the disjunction seems to indicate that the speaker is not quite sure about the number of boys. Similarly, the disjunction in (24) denotes a single car, the color of which the speaker is uncertain about. Quirk et al. (1985) even attribute an idiomatic function to numerals coordinated with or, three or four meaning 'approximately in the range of three or four'. In fact, substituting ten for four, the use of others in (23) gets considerably less acceptable. This is sufficient reason to regard (23) as introducing a single discourse referent with a cardinality in the range of three or four instead of combining two individuals by disjunction.

Bill rented a / the blue or green car from the garage in Tempelhof.

\section{Conclusion}

It has been argued in this paper that the question of why modified numerals like at least three boys resist a referential interpretation is easily solved by adopting the disjunctive interpretation of at least proposed in Krifka (1999). Based on 
disjunction, it predicts that at least can never combine with and never result in an individual, i.e. type e, expression. It has been emphasized that this is not a mere technical solution making use of a particular type system but reflects the basic fact that individuals cannot be combined by disjunction to form a new individual.

Solving a widely discussed problem coincidentally is substantial evidence for Krifka's account. Still, it raises some questions. First, it is claimed that at least phrases do not trigger any proper alternatives, which is crucial for solving the problem of the missing scalar implicature. ${ }^{10}$ This is hard to maintain when taking contrastive statements into consideration. If we assume that the elements in contrast have to be mutual alternatives (cf. Umbach 2004b), examples like (25) show that modified numerals do trigger alternative sets.

(25) At least five boys are wearing black jackets, but at most three / less than three / only three are selling coke.

Secondly, in Krifka (1999) it is taken for granted that the interpretation proposed for at least also applies to more than, which has been tacitly accepted in this paper. It has been found recently, however, that there are various contexts in which superlative quantifiers (at least / at most $n N$ ) and comparative quantifiers (more / less than $n N$ ) differ both in distribution and in meaning. For example, Nouven (2004) and Geurts (2005) both point out that, in downward entailing contexts, superlative quantifiers are less acceptable than comparative ones, and they claim that superlative quantifiers, but not comparative ones, introduce modal operators. ${ }^{11}$

Taking a modal interpretation of disjunction into account, as e.g. proposed by Zimmermann (2000), ${ }^{12}$ it suggests itself to derive the modal interpretation of superlative quantifiers from their disjunctive interpretation, which would confirm both the disjunctive and the modal interpretation. On the other hand, such a correspondence would imply that for comparative quantifiers, which are clearly no modals, the disjunctive interpretation is inadequate. But then the solution to the problem of the blocked referential interpretation suggested in this paper cannot apply to modified numerals which comprise comparative quantifiers, and we have to retum to the initial question in this paper asking why more than three boys does not license a referential reading.

\section{Endnotes}

* I would like to thank Regine Eckardt, Graham Katz and Manfred Krifka, three anonymous referees and the audience at SALT for helpful criticism and valuable comments. 
${ }^{1}$ In a side remark, Szabolcsi relates this distinction to the distinction between categorial and thetic sentences.

2 Szabolcsi departs from standard DRT in using sorted variables for discourse referents where the sort is given by a minimal witness set.

3 In Ebert and Endriss (2004), a 'topic condition' is proposed characterizing the class of quantifiers that can be interpreted referentially and thus qualify as topics. Similar to Szabolcsi, Ebert and Endriss make crucial use of the fact that referential readings support non-maximal anaphors.

${ }^{4}$ In addition to abstraction, there is another operation to form plural antecedents in DRT called summation which forms the sum of individuals, similar to Link's (1983) summation operator. Summation is close to direct introduction of discourse referents in that it relates only to the conditions imposed on the antecedents, but not to conditions introduced by, e.g., the VP. Viewing two ways to form a plural antecedent as redundancy, Hardt (2004) suggested a general mechanism based on inference. A general mechanism of plural formation would, however, miss an important distinction, namely whether antecedents are given by one (or more) referential phrases or by quantification, which is decisive for the range of possible anaphors.

${ }^{5}$ In Umbach (2004a) it is shown that the denotation of the OTHERS corresponds to the set of (proper) alternatives triggered by its co-referent, and vice versa.

${ }^{6}$ De Swart refers to an example given by Szabolcsi where others seems to relate to a co-referent established by a modified numeral:

More than six of our students misunderstood the question. Maybe you will find others, too.

This example may be subsumed under the caveat conceming the others-test because others here clearly means more students who misunderstood the question. In German, the use of mehr ('more') instead of andere ('others') would be obligatory. Note also that the particle too is crucial for the example to be acceptable. Moreover, this example as well as her examples concerning monotone decreasing and non-monotone modified numerals involve comparative quantifiers (more than $n N$, less than $n N$ ), which might indicate that, contrary to the assumption throughout this paper, comparative quantifiers differ from superlative quantifiers (at least $n N$, at most $n N$ ), cf. section 9.

${ }^{7}$ Krifka even includes determiners in the list of expression which can be modified by at least (at least some determiners aren't determiners). I would rather assume that in this example at least operates on the NP denotation.

8 The representation in Krifka (1999) is slightly different because he regards the number word as an adjective combining with a noun and a null determiner, [ $\varnothing$ [three boys]].

To avoid misunderstandings, individuals can of course be joined. This is the basis of Link's plural ontology, establishing a join-semilattice. But the join of 
individuals corresponds to natural language and, whereas the join of predicate denotations corresponds to dis junction.

${ }^{10}$ In the end of his paper Krifka discusses a solution according to which at least phrases do trigger proper alternatives while their ordinary meaning is undefined, which appears counterintuitive. Anyway these alternatives cannot account for the contrasts in (25).

${ }^{11}$ For a comprehensive analysis of comparative quantifiers see Hackl (2000).

12 Compare also Simons, in this volume.

\section{References}

Barwise, Jon and Robin Cooper: 1981, 'Generalized Quantifiers and Natural Language', Linguistics and Philosophy 4, 159-219.

Beghelli, Filippo and Tim Stowell: 1997, 'Distributivity and Negation: The Syntax of each and every', in A. Szabolcsi (ed.) Ways of Scope Taking, Kluwer, Dordrecht, 71-107.

Ebert, Christian and Cornelia Endriss: 2004, 'Wide Scope Indefinites as Aboutness Topics', Proceedings of Sinn \& Bedeutung VIII, Konstanz Linguistics Working papers.

Geurts, Bart: 2005, 'At least et al.', talk at the conference Indefinites and Weak Quantifiers, University of Bruessels.

Hackl, Martin: 2000, 'Comparative Quantifiers', MIT Working Papers in Linguistics.

Hardt, Daniel: 2004, 'Salience, Inference and Plural Anaphora', talk at Sinn \& Bedeutung $L X$, University of Nijmegen.

Kamp, Hans: 2001, 'Presupposition Computation and Presupposition Justification', ESSLLI'01 Reader, University of Helsinki.

Keenan, Edward and Leonard M. Faltz: 1985, Boolean Semantics for Natural Language, Reidel, Dordrecht.

Krifka, Manfred: 1999, 'At least Some Determiners Aren't Determiners', in K. Turner (ed.) The Semantics/Pragmatics Interface from Different Points of View, Elsevier Science, Oxford, 257-291.

Link, Godehard: 1983, 'The Logical Analysis of Plurals and Mass Terms, a Lattice-Theoretic Approach', in R. Bäuerle, C. Schwarze, and A. von Stechow (eds.) Meaning, Use and Interpretation of Language, de Gruyter, Berlin, 302-323.

Nouwen, Rick: 2004, 'On the Semantics of Lower and Upper Bounds', talk at Sinn \& Bedeutung $L X$, University of Nijmegen.

Partee, Barbara: 1987, 'Noun Phrase Interpretation and Type-Shifting Principles', in J. Groenendijk, D. de Jongh, and M. Stockhof (eds.) Studies in 
Discourse Representation Theory and the Theory of Generalized Quantifiers, Foris, Dordrecht, 302-323.

Partee, Barbara and Mats Rooth: 1983, 'Generalized Conjunction and Type Ambiguity', in R. Bäuerle, C. Schwarze, and A. von Stechow (eds.) Meaning, Use and Interpretation of Language, de Gruyter, Berlin, 361383.

Quirk, Randolph, Sidney Greenbaum, Geoffrey Leech, and Jan Svartvik: 1985, $A$ Comprehensive Grammar of the English Language, Longman, London.

de Swart, Henriette: 1999, 'Indefinites between Predication and Reference' Proceedings of SALT 9, Cornell University Press.

Szabolcsi, Anna: 1997, 'Strategies for Scope Taking', in A. Szabolcsi (ed.) Ways of Scope Taking, Kluwer, Dordrecht, 109-154.

Umbach, Carla: 2004a, 'Cataphoric Indefinites', Proceedings of Sinn \& Bedeutung VIII, Konstanz Linguistics Working Papers.

Umbach, Carla: 2004b, 'On the Notion of Contrast in Information Structure and Discourse Structure', Journal of Semantics 21, 155-175.

Zimmermann, Ede: 2000, 'Free Choice Disjunction and Epistemic Possibility', Natural Language Semantics 8, 255-290. 